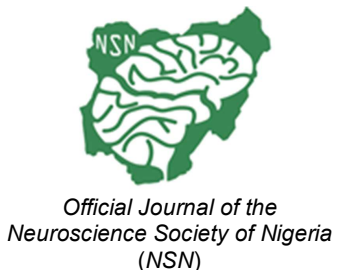

(NSN)

\title{
The Activities of the Central Nervous System Following Ethyl Acetate Extract of Mucuna pruriens Seed Administration in Male BALB/c Mice
}

\author{
Opeyemi S. Osuntokun ${ }^{1,2}$, Gbola Olayiwola ${ }^{3}$, Ayomide K. Oriare ${ }^{1}$, \\ Hephzibah T. Odeniran ${ }^{1}$, Abiodun O. Ayoka ${ }^{4}$
}

\begin{abstract}
${ }^{1}$ Department of Physiology, Faculty of Basic Medical Sciences, Osun State University Osogbo, Nigeria ${ }^{2}$ Department of Physiology, Faculty of Basic Medical Sciences, Federal University Oye Ekiti, Ekiti State, Nigeria ${ }^{3}$ Department of Clinical Pharmacy and Pharmacy Administration, Faculty of Pharmacy, Obafemi Awolowo University, Ile-Ife, Osun State, Nigeria; ${ }^{4}$ Department of Physiological Sciences, Faculty of Basic Medical Sciences, Obafemi Awolowo University, Ile-Ife, Osun State, Nigeria
\end{abstract}

Received: October 2021

Accepted: December 2021

\begin{abstract}
A number of reports showed the beneficial psychotropic effects of many of the Nigerian medicinal plants, but few scientific studies have been carried out as empirical evidence. This study investigated the possible neurobehavioural effects of ethyl acetate extract of Mucuna pruriens (MP) seed in male BALB/c mice. Male BALB/c mice (21/2-3 months old) were grouped into $5(n=6)$, treated with normal saline $(0.1 \mathrm{~mL})$, n-propanol extract of MP $(200,100,50 \mathrm{mg} / \mathrm{kg})$ or reference drug haloperidol (HP) or diazepam (DZP); thereafter, subjected to diverse behavioural models to evaluate the central nervous system (CNS) effects of the extract. A bolus of MP $(200,100$, and $50 \mathrm{mg} / \mathrm{kg})$ decreased the rectal temperature, exploratory activities (locomotion, rearing and grooming), anxiety-like responses (\% openarms time, open-arm entries, and the total number of enclosed arms times). Additionally, a one-shot of intraperitoneal administration of MP decimated the total score of apomorphine-induced stereotyped behaviours. Latency to hexobarbitone-induced sleep increased significantly in the $200 \mathrm{mg} / \mathrm{kg} \mathrm{MP}$, unchanged in the $100 \mathrm{mg} / \mathrm{kg} \mathrm{MP}$, and decreased in the $50 \mathrm{mg} / \mathrm{kg}$ MP treated groups. There was a marked decrease in the markers of convulsion (tonic flexion, extension, clonic convulsion, stupor, and recovery time) following MP treatment, especially the higher doses $(200 \mathrm{mg} / \mathrm{kg}$ and $100 \mathrm{mg} / \mathrm{kg})$. In conclusion, the CNS effects of systemic administration of MP seed are not unrelated to its hypothermic, hypnotic, anxiolytic, and anticonvulsant effects.
\end{abstract}

Key words: Mucuna pruriens seed; Neurobehaviour; Central nervous system; BALB/c mice

\section{INTRODUCTION}

Herbal medicines are widely used globally due to their applicability and therapeutic efficacy coupled with low adverse effects; this is not unrelated to the fact that nature is a rich source of biological and chemical diversity with several health benefits. Despite this, the scientific community, as opposed to folk medicine practitioners has given little attention to the therapeutic use of plants (Carlini 2003; Aghdash 2021). The velvet bean Mucuna pruriens (MP) is widespread in tropical and subtropical regions of the world. It is native to Nigeria, West Africa. It is known as 'Agbala' in Igbo, 'Werepe/Yerepe' in Yoruba and 'Karara' in Hausa. MP is considered a viable source of dietary proteins (Janardhanan et al. 2003) and an established herbal drug in the treatment of nervous disorders (Lampariello et al. 2012).

Phytochemical screening of MP revealed the unusual non-protein amino acid 3-(3,4-dihydroxy phenyl)-Ialanine (L-DOPA). It also contains glutathione, gallic

Correspondence: Opeyemi S. Osuntokun, PhD; Department of Physiology, Faculty of Basic Medical Sciences, Osun State University, Osogbo, Nigeria. E-mail: opeyemi.osuntokun@ fuoye.edu.ng; Phone; +2347066106794; ORCID: 0000-00020780-8729 
acid, and beta-sitosterol. It has such unidentified constituents as mucunine, mucunadine, prurienine, and prurieninine. Other bases isolated from the pods, seeds, leaves and roots include indole-3-alkylamines$\mathrm{N}, \mathrm{N}$-dimethyltryptamine (Yadav et al. 2017). Serotonin is present only in the pods (Khare 2004). The seeds also contain such oils as palmitic, stearic, oleic, and linoleic acids (Mishra and Wagner 2006). Gas chromatography-mass spectrometry analysis of MP showed the presence of such phytochemicals as n-hexadecanoic acid (48.21\%), squalene $(7.87 \%)$, oleic acid (7.62\%), ascorbic acid (3.80\%), and octadecanoic acid (6.21\%) (Bhaskar et al. 2011). Misra and Wagner (2004) reported the presence of two tetrahydroisoquinoline alkaloids namely: 3-methoxy-1,1-dimethyl 6,7dihydroxyl 1,2,3.4 tetra-hydroquinone and 3-methoxy-1, 1-dimethyl-7,8- dihydroxy$1,2,3,4$ tetra-hydroquinone in the MP seed, while Isoquinolines has been reported as a major constituent of n-propanol extract of MP seed (Liu et al. 2016).

Studies demonstrated the activities of (1-[(4hydroxyphenyl) methyl]-1,2,3,4-tetrahydroisoquinoline-6,7-diol) and 1-methyl-1,2,3,4-tetrahydroisoquinoline (1-MeTIQ) as well as N-methyl tetrahydroisoquinoline (N-methyl-TIQ) as unique. but not limited to this neuroprotective and neurorestorative agent (Peana et al. 2019). Previous studies have reported that the activities of MP include antinociception (Harland et al. 2016), free radical scavenging (Wasik et al. 2016) and neuroleptic-like properties (Antkiewicz-Michaluk et al. 2014). The experiments with $[3 \mathrm{H}$ ] apomorphine displacement confirmed that tetrahydroisoquinolies may induce the release of dopamine from dopaminergic terminals. However, owing to their mono-amine oxidase (MAO)-inhibitory influence, tetrahydroisoquinolines do not cause neurodegeneration of the dopaminergic neurons (Antkiewicz-Michaluk et al. 2014).

However, in light of the aforesaid pharmacological characteristics of the phytoconstituents of MP seed, particularly, the L-dopa, and the derivatives of hydroquinone, this study evaluated the possible neurobehavioural effects of MP in male BALB/c mice using a battery of behavioural paradigms that are well-validated for the screening of compounds

\section{MATERIALS AND METHODS}

\section{Mucuna pruriens Seed}

The seeds of Mucuna pruriens (L.) DC. Var were procured in a local market at Oja Oba, Osogbo, Osun State, Nigeria in March 2020; The plant was identified and authenticated by a Taxonomist, Mr. Gabriel Ademoriyo of the Department of Botany, Obafemi Awolowo University, Ile-Ife, Osun State, Nigeria, and a voucher specimen number IFE18007 was assigned. The seeds were shade dried and milled into a fine powder using a mechanical grinder. The powdered plant material was macerated with ethyl acetate. The extract was then filtered with filter paper (Whatman No. 1) under reduced pressure using a rota evaporator at $40^{\circ} \mathrm{C}$. The characterization of ethyl acetate extract of MP seed contained the maximum concentration of anthraquinones, carbohydrates, alkaloids, flavonoids, and almost devoid of glycosides, saponins, tannins, and steroids (Peana et al. 2019).

\section{Ethical Approval}

This study was designed and carried out in accordance to the lay-down rules of the Health Research Ethics Committee of the College of Health Sciences, Osun State University, Osogbo, Nigeria which is in line with the National Institute of Health (NIH) in the "Guide to the care and use of animals in Research and Teaching" (National Institute of Health, USA, 2011).

\section{Animal Handling}

A total of 180 male BALB/c mice (21/2-3 months old, 20-23 g) were kept in propylene cages under a natural $12 \mathrm{~h}$ light-dark cycle. The animals were housed in groups of six mice per cage with free access to feed and water ad libitum and allowed to acclimatize to the laboratory conditions for 10 days before the commencement of the behavioural study, and we also ensured that each mouse was used once.

\section{Drugs and Extract}

Diazepam (DZP) (Sigma-Aldrich Co. USA), haloperidol (HP) (Sigma-Aldrich Co. USA), and ethyl acetate extract of MP seed were dissolved in normal saline.

\section{Treatment Schedules}

For each experiment, 30 mice were shared into 5 groups $(n=6)$ to receive the MP vehicle (normal saline, $0.1 \mathrm{~mL})$, MP $(200,100$ or $50 \mathrm{mg} / \mathrm{kg}$ body weight) (Gbotolorun et al. 2018), and a reference drug, haloperidol (HP) (5 mg/kg body weight). All treatment schedules were administered intraperitoneally as a single bolus.

\section{Behavioural Assessment}

Six battery of tests (rectal temperature, open-field exploratory behaviour, elevated plus maze test, apomorphine-induced stereotyped behaviour, hexobarbitone induced hypnosis, and maximal electric shock) were used to evaluate the thermoregulatory, anxiolytic, psychotic, sedative, and anticonvulsant effects of MP seed respectively, while a new set of 30 mice were used for each experiment in order to avoid the effects of battery of tests. These battery of tests were carried out during daylight (between 8:00 am and $2 \mathrm{pm}$ ). Moreover, all the experiments were done in a soundproofed room. The 
behaviour was video recorded through a camera (DS126311; Canon Inc., Tokyo Japan) positioned above the testing apparatus and scored by an experienced but blinded experimenter in the Physiology Laboratory of the Osun State University, Nigeria.

\section{Rectal Temperature}

The rectal temperature was measured with a siliconized thermostat probe inserted $2 \mathrm{~cm}$ into the rectum of the mice as described by Moreira et al. (2010). The probe was held in the rectum until a stable rectal temperature was taken for $20 \mathrm{~s}$, with an accuracy of $0.1^{\circ} \mathrm{C}$. The rectal temperature was recorded twice: before (T1) and $1 \mathrm{~h}$ after (T2) treatment. The temperature variation (DT) was estimated as DT = T2 - T1 for each mouse.

\section{Open Field Exploratory Activities}

Each mouse was placed in the centre of the open field and left to freely explore for $5 \mathrm{~min}$. The test chamber was cleaned with $70 \%$ ethanol before each session while the total number of gridlines crossed by each animal was recorded (Osuntokun et al. 2021). In addition, the number of grooming and rearing were recorded.

\section{Elevated Plus-Maze Anxiolytic Test} Each mouse was placed in the centre of the maze facing an enclosed arm

and was observed for $5 \mathrm{~min}$. The indices of anxiety-like behaviour were defined as the percentage of open-arm entries relative to the total number of arm entries, and the percentage of time spent in the open arms to the total time spent in both arms. An arm entry was recorded when a mouse placed all four paws onto an arm. An increase in these parameters indicated an anxiolytic-like effect. The total number of closed-arm entries was used as

Table 1: Effects of Mucuna pruriens Seed on the Activities of Mice Evaluated in the Open Field Chamber

\begin{tabular}{llll}
\hline \multicolumn{2}{c}{ Open field arena } & \multicolumn{2}{c}{ Activity chamber } \\
\hline Treatment group & $\begin{array}{l}\text { Locomotor } \\
\text { (Number of crossing) }\end{array}$ & Rearing & Grooming \\
\hline Control & $52.40 \pm 2.94$ & $3.20 \pm 0.20$ & $0.20 \pm 0.20$ \\
MP $200 \mathrm{mg} / \mathrm{kg}$ & $81.20 \pm 10.95^{\alpha}$ & $1.25 \pm 0.25^{\alpha}$ & $9.60 \pm 2.21^{\alpha}$ \\
MP $100 \mathrm{mg} / \mathrm{kg}$ & $67.00 \pm 10.51^{\alpha}$ & $0.75 \pm 0.48^{\alpha}$ & $1.80 \pm 0.37^{\alpha}$ \\
MP $50 \mathrm{mg} / \mathrm{kg}$ & $58.60 \pm 4.92^{\delta}$ & $0.50 \pm 0.29^{\alpha}$ & $0.80 \pm 0.58^{\alpha}$ \\
HP $(5 \mathrm{mg} / \mathrm{kg})$ & $91.20 \pm 2.65^{\alpha \mu}$ & $0.28 \pm 0.24^{\alpha \delta}$ & $0.20 \pm 0.20^{\delta \mu}$ \\
\hline
\end{tabular}

$\alpha, \delta, \mu$ - Significantly different from control $(p=0.0001)$, MP $(200 \mathrm{mg} / \mathrm{kg})(p=$ $0.0288), M P(100 \mathrm{mg} / \mathrm{kg})(p \leq 0.05)$ and MP, respectively an index of locomotor activity (Moreira et al. 2010).

Apomorphine-Induced Stereotyped Behaviour Apomorphine $(0.5 \mathrm{mg} / \mathrm{kg})$ was administered subcutaneously (sc) 30 min either post MP, HP or DZP treatments. Behaviour was observed for $10 \mathrm{~s}$ at every $10 \mathrm{~min}$ for $90 \mathrm{~min}$ while each mouse was in the arena of the open field apparatus $(25 \times 25 \times 30 \mathrm{~cm}$ square acrylic boxes).

Stereotyped behaviour was scored as earlier reported by Moreira et al. (2010) based on the scale proposed by Setler et al. (1976); $0=$ asleep or stationary, 1 = active, 2 = predominantly active but with bursts of stereotyped sniffing, rearing, or headbobbing but with locomotor activity still present, $3=$ constant stereotyped activity such as sniffing, rearing, or head-bobbing but with locomotor activity still present, 4 = constant stereotyped activity limited to

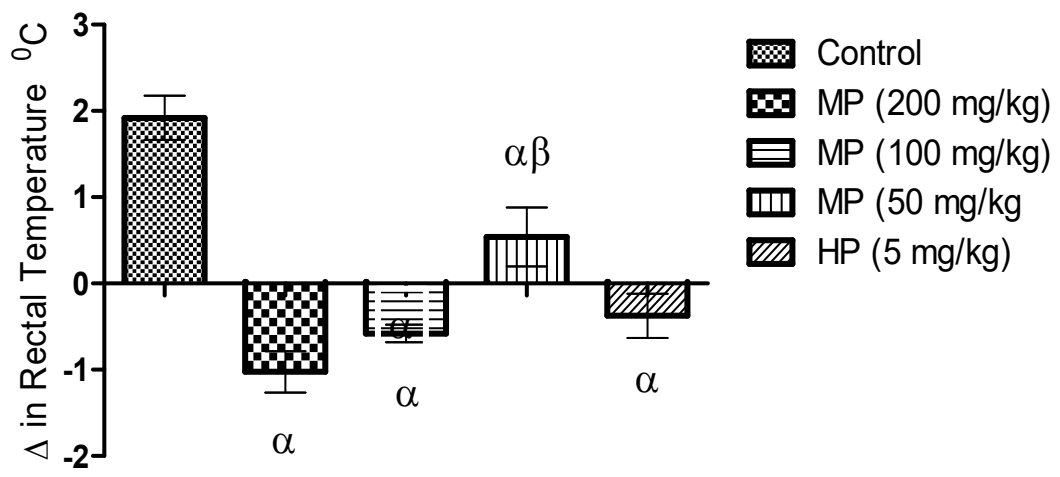

Fig. 1: Effects of Ethyl Acetate Extract of Mucuna pruriens Seed on Rectal Temperature. $\alpha, \beta$ - Significantly different from control $(p=0.0001)$ and other MP treatments groups $(p=0.0031)$, respectively.

one location, $5=$ constant stereotyped activity but with bursts of licking and/or gnawing and biting, $6=$ continual licking and/or gnawing of cage grids.

\section{Hexobarbitone-Induced Hypnosis}

Thirty minutes after all the mice were treated with normal saline, graded doses of MP (200, 100 or $50 \mathrm{mg} / \mathrm{kg}$, i.p.), or HP. Each mouse received hexobarbitone $(50 \mathrm{mg} / \mathrm{kg}$ body weight) and thereafter, placed in the arena of the open field apparatus $(25 \times 25 \times$ $30 \mathrm{~cm}$ square acrylic boxes) for close observation (Moreira et al., 2010). The latency to the loss of righting reflex and the total duration of sleep were recorded using stopwatches. Sleeping time was measured by the loss of righting reflex, with the recovery of this reflex considered the hypnosis endpoint. 


\section{Anticonvulsant Assessment of MP using} Electroconvulsiometer

Adult male mice were grouped into five to receive intraperitoneal administration of normal saline, graded doses of MP (200, 100 or $50 \mathrm{mg} / \mathrm{kg}$ i.p), or HP. In a bid to confirm the anticonvulsant effects of these MP, 30 min after the administration, animals across the experimental groups were kindled for seizure at sub-maximal electric shock (SMEs) at a current of $99 \mathrm{~mA}$, pulse width of 0.5 at $100 \mathrm{~Hz}$ for $2 \mathrm{~s}$ using electroconvulsiometer (Ugo Basile). Each convulsed mouse was observed for the time (in seconds) taken to experience tonic flexion, tonic extension, clonic convulsion, stupor, and righting reflex, while the percentage mortality was recorded (Olaibi et al. 2014).

Table 2: Effects of the Mucuna pruriens Seed on the Behaviour of Mice Evaluated in Elevated Plus-Maze

\begin{tabular}{llll}
\hline Treatment & $\%$ Open-arms time & Open-arm entries & $\begin{array}{l}\text { Total number of } \\
\text { Enclosed-arm time }\end{array}$ \\
\hline Normal saline & $1.18 \pm 0.66$ & $1.00 \pm 0.41$ & $292.70 \pm 2.40$ \\
MP $(200 \mathrm{mg} / \mathrm{kg})$ & $16.38 \pm 2.49^{\alpha}$ & $6.25 \pm 0.63^{\alpha}$ & $229.00 \pm 6.11^{\alpha}$ \\
MP $(100 \mathrm{mg} / \mathrm{kg})$ & $8.75 \pm 3.32^{\alpha}$ & $2.25 \pm 0.48^{\delta}$ & $274.0 \pm 3.18^{\delta}$ \\
MP $(50 \mathrm{mg} / \mathrm{kg})$ & $6.63 \pm 2.89^{\delta}$ & $3.25 \pm 0.48^{\delta}$ & $280.00 \pm 1.16^{\delta}$ \\
HP $(5 \mathrm{mg} / \mathrm{kg})$ & $17.44 \pm 2.58^{\mathrm{a} \#}$ & $4.25 \pm 0.75^{\beta \delta}$ & $227.00 \pm 1.00^{\alpha}$ \\
\hline
\end{tabular}

$\alpha, \delta$, \# - Significantly different from control ( $p \leq 0.0001)$, MP $(200 \mathrm{mg} / \mathrm{kg})(p \leq 0.05), \operatorname{MP}(100$ $\mathrm{mg} / \mathrm{kg})(\mathrm{p} \leq 0.05)$ and MP $(50 \mathrm{mg} / \mathrm{kg})(\mathrm{p}=0.0047)$, respectively

\section{RESULTS}

Effects of Ethyl Acetate Extract of Mucuna pruriens Seed on Rectal Temperature The rectal temperature decreased significantly $(p=0.0001)$ across the $\mathrm{MP}$, and haloperidol treatment groups compared with the control (Fig. 1).

\section{Effects of Mucuna pruriens Seed on the Activities of Mice} Evaluated in Open Field Chamber There was a significant increase $(p$ $=0.0001$ ) in the locomotor activities of the treated mice except for the MP (50 $\mathrm{mg} / \mathrm{kg})$ treatment group which had no significant $(p=$ 0.3892) difference compared with the control. The number of rearing decreased significantly ( $p=0.0001$ ) in all the treatment groups compared with the control. Additionally, the number of grooming behaviours increased significantly $(p=0.0001)$ across the treatment groups except for the reference dose HP (Table 1).

Effects of the Mucuna pruriens Seed on the Behaviours of Mice Evaluated in Elevated PlusMaze

The percentage open-arms time increased significantly ( $p=0.0006$ ) across the treatment groups except the MP $(50 \mathrm{mg} / \mathrm{kg})$ treated mice, where there was no significant $(p=0.0782)$ difference compared with the control. In addition, percentage open-arms time decreased significantly $(p=0.0430)$ in the MP $(50 \mathrm{mg} / \mathrm{kg})$ compared with MP $(200 \mathrm{mg} / \mathrm{kg})$ treated mice, while the HP treatment had increased $(p=$ $0.0266)$ percentage open-arms time relative to MP (50 mg/kg) (Table 2).

The number of openarms entries increased significantly $(p=0.000$ 1) in all the treatment groups except the MP (50 $\mathrm{mg} / \mathrm{kg}$ ) which was not significantly different ( $p=0.0941$ ) compared with the control. Moreover, among the MP treatment groups, there was a significant decrease $(p=0.0013)$ in the number of open-arm entries exhibited by the MP (100 mg/kg), and MP $(50 \mathrm{mg} / \mathrm{kg})$ treatment groups relative to their MP (200 mg/kg) counterpart (Table 2).

The total number of enclosed arm times decreased significantly ( $p=0.0001$ ) across the treatment groups compared with the control. There was a significant increase in the total number of enclosed arms times in the MP (50 mg/kg), and MP (100 mg/kg) treatment

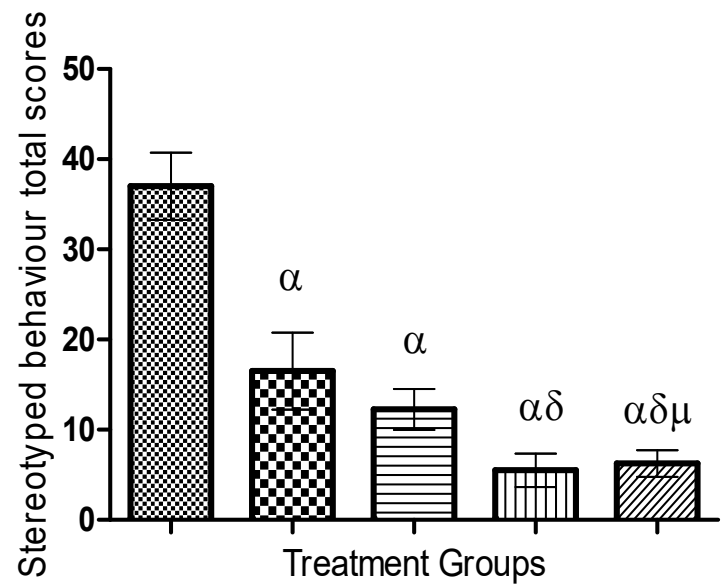

Fig. 2: Effects Mucuna pruriens seed on the Apomorphine-Induced Stereotyped Behaviour. $\alpha, \delta$, \# - Significantly different from control $(p=0.0001)$, MP $(200 \mathrm{mg} / \mathrm{kg})(p=0.0399), \operatorname{MP}(100 \mathrm{mg} / \mathrm{kg})(p=0.05)$ and MP $(100 \mathrm{mg} / \mathrm{kg})(p=$ $0.0425)$, respectively

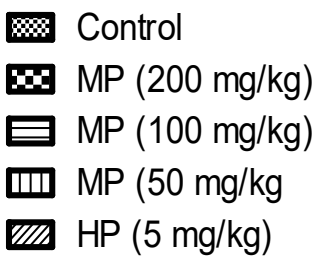


groups relative to MP $(200 \mathrm{mg} / \mathrm{kg})$. In addition, the total number of enclosed arms times decreased significantly $(p=0.0001)$ following HP treatment compared with MP (50 mg/kg) (Table 2)

Effects Mucuna pruriens Seed on the Apomorphine-Induced Stereotyped Behaviour

The markers of stereotyped behaviours decreased significantly ( $p=0.0001$ ) across the treatment groups compared with the control. Moreover, stereotyped behaviours were decreased significantly $(p=0.0399)$ by the MP (50 mg/kg), and HP compared with MP (200 $\mathrm{mg} / \mathrm{kg}$ ) treated mice. While there was no significant $(p=0.0615)$ difference in the stereotyped behaviours between MP (200 mg/kg) and MP (100 $\mathrm{mg} / \mathrm{kg}$ ) treated mice (Fig. 2).

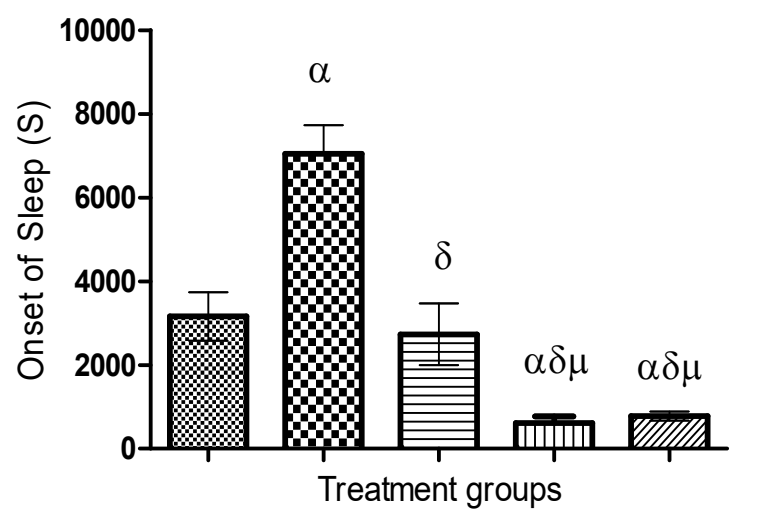

Fig. 3: Effects of Mucuna pruriens Seed on Sleep Latency Following Hexobarbitone Administration. $\alpha, \delta, \mu$ - Significantly different from control ( $p=$ $0.0121), M P(200 \mathrm{mg} / \mathrm{kg})(\mathrm{p}=0.0001), \mathrm{MP}(100 \mathrm{mg} / \mathrm{kg})(\mathrm{p}=0.05)$ and MP (100 $\mathrm{mg} / \mathrm{kg})(p=0.0071)$, respectively

Effects of Mucuna pruriens Seed on Sleep Latency Following Hexobarbitone Administration There was significant $(p=0.0121)$ delay in the onset of sleep following MP $(200 \mathrm{mg} / \mathrm{kg})$ treatment, while MP (100 mg/kg) had no significant $(p=0.6734)$ effect compared with the control. However, MP (50 mg/kg), and HP treatment significantly $(p=0.0006)$ decreased the latency to sleep compared with the control. In addition, among the treatment groups, significant $(p=0.0001)$ decrease observed in the onset of sleep exhibited by the MP (100 mg/kg), MP (50 $\mathrm{mg} / \mathrm{kg}$ ), and HP treatment compared with MP (200 mg/kg) treatment group (Fig. 3)

\section{Effects of Mucuna pruriens Seed on Electrically- Induced Convulsed Male Mice}

The duration of tonic flexion exhibited by the mice decreased significantly $(p=0.0001)$ in the MP (200 $\mathrm{mg} / \mathrm{kg}$ ) and DZP treated groups compared with the control. The duration of the tonic extension decreased markedly ( $p=0.0001)$ across the treatment groups, except the MP $(50 \mathrm{mg} / \mathrm{kg})$ treated. The time taken by the treated mice to exhibit clonic convulsion decreased significantly ( $p=0.0001)$ in the MP (200 $\mathrm{mg} / \mathrm{kg}$ ), and DZP treated groups. There was a marked decrease in the duration of stupor and recovery (righting reflex) across the treatment groups. Moreover, there was a decrease in the percentage of mortality across the treatment group compared with the control (Table 3).

\section{DISCUSSION}

Previous in-vitro and in-vivo studies on MP extracts have revealed the presence of substances that exhibit a wide variety of pharmacological effects like anti-diabetic, anti-inflammatory, neuroprotective, and anti-oxidant properties due to the presence of Ldopa, a precursor of the neurotransmitter dopamine (Misra and Wagner 2007; Lampariello et al. 2012). This present study for the first time revealed a wide spectrum effects of ethyl acetate extract of MP on the neurobehaviours of male $\mathrm{BALB} / \mathrm{c}$ mice.

A significant decrease in the rectal temperature of the MP-treated mice is a pointer to the hypothermic effect of the MP seed. This was most evident in the highest dose (MP 200 $\mathrm{mg} / \mathrm{kg}$ ). Studies have shown the beneficial effects of hypothermia. Zhang et al. (2021) reported that mild hypothermia is one of the potential measures for the management of a high intracranial pressure sequel to traumatic brain injuries in adults.

Findings from both experimental and clinical studies have shown that mild or moderate hypothermia led to neuroprotection and improved functional outcomes in various models of brain and spinal cord injury (Dietrich et al. 2009; Docherty et al. 2018). Hypothermia increases survival and quality of life for patients suffering from ischaemic insults (cardiac arrest, stroke, and neurogenic fever) following brain trauma (Darwazeh and Yan 2013).

The free radical production, inflammation, excitotoxicity of the vulnerable neuronal tissue, and intracranial pressure has been implicated in the pathomechanism of hypothermia (Andresen et al. 2015). In addition, glutamatergic receptors: 2- amino3- hydroxy- 5- methyl- 4 isoxazole propionic acid (AMPA), and N- Methyl- D-aspartate acid (NMDA) expression of patterns may be affected by temperature modifications (Lee et al. 2017). However, It is a fact that dopamine is one of the important neurotransmitters saddled with several homeostatic functions, including thermoregulation in the hypothalamic regions (Zheng and Hasegawa 2015), interestingly, MP is well known as a natural source of L-dopa (3,4-dihydroxyphenylalanine), a 
precursor of dopamine. Therefore, MP-induced hypothermia in this study may be the dopaminergic effects of MP.

Enhancement of general locomotion (open field arena) and attenuation of the novel environment(activity cage) induced locomotion may serve as a pointer to the activities of the MP in the CNS. Consistent data from the elevated plus-maze test in this study also demonstrated the anxiolytic properties of MP. This finding is in tandem with the report of Singh et al. (2019) that MP at the doses of 200 and $400 \mathrm{mg} / \mathrm{kg}$ could serve as a potent anxiolytic agent.

In this present study, treatment with MP seed decimated the apomorphine-induced stereotyped behaviour. It is worthy of note, that the lowest dose (50 $\mathrm{mg} / \mathrm{kg}$ ) abrogated this behaviour more, an attribute similar to what is obtainable in an atypical antipsychotic drug. This finding is in line with the report of Moreira et al. (2010) that the property of a drug to antagonize apomorphine-induced stereotyped behaviour in rodents is correlated with potential receptor agonists recovers REM sleep in mice (Kesner and Lovinger 2020). It is worthy of note therefore, that MP $(50 \mathrm{mg} / \mathrm{kg})$ which antagonized the apomorphine-induced stereotyped behaviour also shortened the sleep onset, another suggestive evidence of the CNS effects of MP seed administration.

The MP pretreatment decreased the duration of tonic flexion, tonic extension, clonic convulsion, stupor, and righting reflexes/recovery; a shred of suggestive evidence of anticonvulsant effects. This is not unrelated to the hypothermic, dopaminergic activities of the anthraquinones in the MP seed. Anthraquinones, one of the major active components of the ethyl acetate extract of MP have been implicated in the neuroprotective therapeutic roles in some CNS dysfunctions including cerebral ischaemic stroke, intracerebral haemorrhage, traumatic brain injury, brain tumour, Alzheimer's disease, and depression (Cao et al. 2017; Li et al. 2019). Csernyus et al. (2020) also implicated hypothermia in the reduction

Table 3 Effects of Mucuna pruriens Seed on Electrically-Induced Convulsed Male BALB/c Mice

\begin{tabular}{lllllll}
\hline $\begin{array}{l}\text { Treatment } \\
\text { Groups }\end{array}$ & $\begin{array}{l}\text { Tonic } \\
\text { Flexion (s) }\end{array}$ & $\begin{array}{l}\text { Tonic Hind-Limb } \\
\text { Extension (s) }\end{array}$ & $\begin{array}{l}\text { Clonic } \\
\text { Convulsion (s) }\end{array}$ & Stupor (s) & $\begin{array}{l}\text { Righting Reflex } \\
\text { (s) }\end{array}$ & $\begin{array}{l}\text { Mortality } \\
\text { (\%) }\end{array}$ \\
\hline Control $(0.2 \mathrm{~mL})$ & $11.40 \pm 0.68$ & $17.00 \pm 0.55$ & $10.20 \pm 0.37^{\circ}$ & $176.6 \pm 3.14$ & $162.40 \pm 2.16$ & 100 \\
MP $(200 \mathrm{mg} / \mathrm{kg})$ & $7.60 \pm 0.51^{\alpha}$ & $10.20 \pm 0.97^{\alpha}$ & $5.80 \pm 0.66^{\alpha}$ & $84.00 \pm 3.27^{\alpha}$ & $119.80 \pm 1.93 \alpha$ & 40 \\
MP $(100 \mathrm{mg} / \mathrm{kg})$ & $9.60 \pm 0.68^{\delta}$ & $13.20 \pm 0.73^{\alpha \delta}$ & $9.80 \pm 0.73^{\delta}$ & $131.60 \pm 1.81 \alpha^{\delta}$ & $129.00 \pm 1.82^{\alpha \delta}$ & 60 \\
MP (50 mg/kg) & $10.20 \pm 0.58^{\delta}$ & $15.20 \pm 0.86^{\delta}$ & $8.80 \pm 0.37^{\delta}$ & $122.80 \pm 1.39 \alpha^{\delta \mu}$ & $147.80 \pm 2.13^{\alpha \delta \#}$ & 60 \\
DZP $(5 \mathrm{mg} / \mathrm{kg})$ & $6.40 \pm 0.68^{\alpha}$ & $4.00 \pm 0.32^{\alpha \mu \#}$ & $5.20 \pm 0.37^{\alpha \mu \#}$ & $51.60 \pm 2.38^{\alpha \mu \#}$ & $21.40 \pm 1.36^{\alpha \delta \mu \#}$ & 20
\end{tabular}

$\alpha, \delta, \mu, \#$ - Significantly different from control $(p=0.0001), M P(200 \mathrm{mg} / \mathrm{kg})(p=0.0001), \mathrm{MP}(200 \mathrm{mg} / \mathrm{kg})(p=0.05), \mathrm{MP}$ $(100 \mathrm{mg} / \mathrm{kg})(p=0.0001)$ and MP $(50 \mathrm{mg} / \mathrm{kg})(p=0.0001)$, respectively

antipsychotic actions. An increase in sleep latency is evident in the antagonism of hexobarbitone-induced hypnosis following MP seed treatment, particularly, the highest dose $(200 \mathrm{mg} / \mathrm{kg})$. This may not be unrelated to the presence of flavonoids in the ethyl acetate extract of MP. Flavonoids are both naturally occurring and synthetic, and are known to have multiple effects on the activation of ionotropic receptors for $y$-aminobutyric acid (GABA), the major inhibitory neurotransmitter in the brain (Hinton et al. 2017). Therefore, it could be inferred that the antipsychotic effects demonstrated by the ethyl acetate extract of MP treatment in this study is arguably attributable to the flavonoid therein. Wasowski and Marder (2012) reported that flavonoids are prominent drugs in the treatment of mental disorders, and can also be used as tools to study modulatory sites at GABA type A. Moreover, previous report has revealed that the dopamine-depleted state is marked by an apparent suppression of slow-wave sleep (SWS) and a complete suppression of rapid eye movement sleep (REM) sleep, while treatment with dopaminergic receptor 2 (D2) (but not D1) dopamine of neurologic functions through a variety of mechanisms: rapid reduction in neurotransmitter release, alternation of kinetics in voltage-gated ion channels, decreased cerebral metabolism, and reversible disruption of the network synchrony. Other important ways in which hypothermia affects central neuronal excitability include increased input resistance, reduced synaptic transmission, decreased amplitude in population spikes, and increased spike duration. It is a common belief that dopamine subserves its traditional anticonvulsant effect by stimulating the D2 receptor in the forebrain (Starr 1996; Bernedo et al. 2015), while selective D1 agonists could serve as potent pro-convulsant agents (Gangarossa et al. 2011; Dubravka et al. 2016).

\section{Conclusion}

The present findings suggest that MP seed enhances hypothermia, antipsychotic, and anticonvulsant effects in male BALB/c mice. These effects may be traceable to the presence of flavonoids, L- dopa, a precursor of dopamine, and anthraquinones. Further 
investigation is required on the mechanism of anticonvulsion of MP.

\section{Grants and Financial Support}

Nil.

\section{Conflict of Interest}

None declared.

\section{Acknowledgement}

The authors of this research are grateful to Mr. E. A. Adeyemi, Pharmacology Department, Faculty of Pharmacy, Obafemi Awolowo University, lle-lfe, Nigeria; for his immense technical contribution towards the success of this research.

\section{Authors Contribution}

OS: Conceptualization, visualization, methodology, formal analysis, validation, writing original and final draft of manuscript; GO: resources, investigation, OS, $\mathrm{AK}$ and HT: data curation, project administration; GO and $\mathrm{AO}$ : Supervision, review and editing.

\section{REFERENCES}

Antkiewicz-Michaluk, L., Wasik, A., Michaluk, J (2014) 1-Methyl-1,2,3,4-Tetrahydroisoquinoline, an endogenous amine with unexpected mechanism of action: new vistas of therapeutic application. Neurotoxicol Res. 25:1-12.

Wasik, A., Romanska, I. and Antkiewicz-Michaluk, L. (2016) Neuroprotection effect of an endogenous amine, $1 \mathrm{MeTIQ}$ against disturbances in dopamine release induced by the neurotoxin, 6-OHDA: In vivo microdialysis study [abstract]. Movement Disorder. 31 (suppl 2).

Aghdash, S.N. (2021) Herbal medicine in the treatment of epilepsy. Curr Drug Targets. 22:3. doi: 10.2174/1389450121999201001152221.

Andresen, A., Gazmuri, J.G., Marín, A., Regueira, T. and Rovegno, M (2015) Therapeutic hypothermia for acute brain injuries. J Trauma Resuscitation Emergency Med. 23:42.

Bernedo, P.V.E., Buchholz, H.G., Gartenschläger, M., Breimhorst, M., Schreckenberger, M. and Werhahn, K.J. (2015) Reduced D2/D3 Receptor Binding of Extrastriatal and Striatal Regions in Temporal Lobe Epilepsy. PLoS ONE. 10(11): e0141098.

Bhaskar, A., Nithya, V. and Vidhya, V.G. (2011) Phytochemical evaluation by GC-MS and antihyperglycemic activity of Mucuna pruriens on streptozotocin-induced diabetes in rats. J Chem Pharmaceut Res. 3:689-696.

Cao, Y.J., Pu, Z.J., Tang, Y.P., Shen, J., Chen, Y.Y., Kang, A., et al. (2017). Advances in bio-active constituents, pharmacology and clinical applications of rhubarb. Chinese Med. 12:36. https://doi.org/10. 1186/s13020-017-0158.

Carlini, E.A. (2003) Plants and the central nervous system. Pharmacol Biochem Behav. 75:501-512.

Csernyus, B., Szabó, A., Zátonyi, A., Hodován, R., Lázár, C., Fekete, Z (2020) Recent antiepileptic and neuroprotective applications of brain cooling. Seizure 82:80-90.

Darwazeh, R. and Yan, Y. (2013) Mild hypothermia as a treatment for central nervous system injuries: Positive or negative effects. Neural Regen Res. 8(28): 2677-2686. https://doi.org/10.3969/j.issn. 1673 -5374.2013 .28 .010 .

Dietrich, W.D., Atkins, C.M. and Bramlett, H.M. (2009) Protection in animal models of brain and spinal cord injury with mild to moderate hypothermia. J Neurotrauma. 26(3):301-312.

Docherty, A., Emelifeonwu, J. and Andrews, P.J.D. (2018) Hypothermia after traumatic brain injury. JAMA. 320(21):2204-2206.

Dubravka, S.S., Nela, P., Smolders, I.J., Fogel, W.A., De-Deurwaerdere, P. and Di-Giovanni, G. (2016) Monoaminergic mechanisms in epilepsy may offer innovative therapeutic opportunity for monoaminergic multi-target drugs. Frontiers Neurosci. 10:492.

Gangarossa, G., Di, B.M., O'Sullivan, G.J., Dunleavy, M., Alcacer, C. and Bonito-Oliva, A. (2011) Convulsant doses of a dopamine D1 receptor agonist result in Erk-dependent increases in Zif268 and Arc/Arg3.1 expression in mouse dentate gyrus. PLoS ONE. 6(5):e19415.

Gbotolorun, S.C., Isah, K.P. and Okafor, I.A. (2018) Sub-acute safety study of Mucuna pruriens extract on liver profile. Nig Q J Hosp Med. 28(2):100-102.

Harland, A.A., Bender, A.M., Griggs, N.W., Gao, C., Anand, J.P., Pogozheva, I.D. et al. (2016). Effects of $\mathrm{N}$-substitutions on the tetrahydroquinoline (THQ) core of mixed-efficacy $\mu$-opioid receptor (MOR)/ठ-opioid receptor (DOR) ligands. J Med Chem. 59(10):49854998.

Hinton, T., Hanrahan, J.R. and Johnston, G.A.R (2017) Flavonoid Actions on Receptors for the Inhibitory Neurotransmitter GABA, Flavonoids - From Biosynthesis to Human Health, Goncalo C. Justino, IntechOpen, doi:10.5772/67971.

Janardhanan, K., Gurumoorthi, P. and Pugalenthi, M. (2003) Nutritional potential of five accessions of a South Indian tribal pulse, Mucuna pruriens var. utilis. Part I. The effect of processing methods on the contents of L-Dopa phytic acid, and oligosaccharides. Journal of Tropical and Subtropical Agro-ecosystems 1:141-152.

Kesner, A.J. and Lovinger, D.M. (2020) Cannabinoids, endocannabinoids and sleep. Frontiers Mol Neurosci. 13:125 doi:10.3389/fnmol.2020.00125

Khare, C.P. (2004) Encyclopedia of Indian Medicinal Plants. Berlin, Heidelberg: Springer Verlag. 
Lampariello, L.R., Cortelazzo, A., Guerranti, R., Sticozzi, C. and Valacchi, G. (2012) J Trad Complementary Med. 2(4):331-339.

Lee, J.H., Zhang, J. and Yu, S.P. (2017) Neuroprotective mechanisms and translational potential of therapeutic hypothermia in the treatment of ischemic stroke. Neural Regen Res. 12(3):341350

Li, X., Chu, S., Liu, Y. and Chen, N (2019) Neuroprotective effects of anthraquinones from rhubarb in central nervous system diseases. EviBased Complementary Alternat Med. 2019:3790728. https://doi.org/10.1155/2019/3790728 Liu, W., Ma, H., DaSilva, N.A., Rose, K.N., Johnson, S.L., Zhang, L., et al. (2016) Development of a neuroprotective potential algorithm for medicinal plants. Neurochem Int. 100:164-177.

Mishra, L. and Wagner, H. (2006) Lipid derivatives from Mucuna pruriens seeds. Indian J Chem. 45:8014.

Misra, L. and Wagne, H. (2007) Extraction of bioactive principles from Mucuna pruriens seeds. Indian J Biochem Biophysics. 44:56-60.

Misra, L. and Wagner, H. (2004) Alkaloidal constituents of Mucuna pruriens seeds. Phytochem. 65:2565-2567

Moreira, E.L.G., Rial, D.F.S., Duarte, C.R., deCarvalho, H., Horst, M.G., Pizzolatti, R.D.S., et al. (2010) Central nervous system activity of the proanthocyanidin- rich fraction obtained from croton celtidifoliusin rats. J Pharm Pharmacol. 2:101-108.

National Research Council (2011) Recommended dietary allowances (10th ed.). Washington, DC: National Academy Press.

Olaibi, O.K., Osuntokun, O.S. and ljomone, O.M. (2014) Effects of chronic administration of effects of chronic administration of gabapentin and carbamazepine on the histomorphology of the hippocampus and striatum. Annals Neurosci. 21(2):57-61.
Osuntokun, O.S., Ademinkanra, A.J., Atere, T.G., Olayiwola, G., Adedokun, K.I. and Adekomi, D.A. (2021) Graded doses of grape seed methanol extract attenuated ataxic movement, cerebellocortical toxicity, and impairment following chronic carbamazepine treatment in male Wistar rats. Epilepsy Behav. 114(Pt A):107484.

Peana, A.T., Bassareo, V. and Acquas, E. (2019) Not just from ethanol tetrahydroisoquinolinic (TIQ) derivatives: from neurotoxicity to neuroprotection. Neurotox Res. 36:653-668.

Setler, P., Sarau, H. and McKenzie, G. (1976) Differential attenuation of some effects of haloperidol in rats given scopolamine. Eur $\mathrm{J}$ Pharmacol. 39(1):117-126. https://doi.org/10.1016/0014-2999(76) 90119-9.

Singh, S., Gupta, P. and Gupta, R. (2019) Evaluation of the anti-anxiety activity of Mucuna pruriens. J Drug Delivery Therapeut. 9(4-A):104-107.

Starr, M. S. (1996) The role of dopamine in epilepsy. Synapse. 22(2):159-194.

Wasowski, C. and Marder, M. (2012) Flavonoids as GABAA receptor ligands: the whole story? J Exp Pharmacol. 4: 9-24.

Yadav, M.K., Upadhyay, P., Purohit, S., Pandey, B.L., Shah, H. (2017) Phytochemistry and pharmacological activity of Mucuna pruriens $A$ review. Int J Green Pharm. 11(2):69-73.

Zheng, X. and Hasegawa, H. (2015) Central dopaminergic neurotransmission plays an important role in thermoregulation and performance during endurance exercise. Eur J Sport Sci. 16(7):818-828 doi: 10.1080/17461391.2015.1111938.

Zhang, B., Gu, Q., Chen, X., You, Y., Chen, M., Qian, Y., et al. (2021) temperature variability does not attenuate the beneficial effects of therapeutic hypothermia on cellular apoptosis and endoplasmic reticulum stress in the cerebral cortex of a swine cardiac arrest model. Neurocritical Care. 34(3):769780. 